\title{
A FRAGMENTAÇÃO DA FLORESTA É UM INDICADOR DE COMPACTAÇÃO DO SOLO EM SISTEMA FAXINAL?
}

\author{
Valdemir Antoneli \\ Pós-Graduação em Geografia. Guarapuava-PR \\ Universidade Estadual do Centro-Oeste - UNICENTRO \\ vaantoneli@gmail.com \\ Tais de Oliveira \\ Universidade Estadual do Centro-Oeste - UNICENTRO, Campus de Irati- PR \\ thizoliver@gmail.com \\ João Anésio Bednarz \\ Universidade Estadual do Centro-Oeste - UNICENTRO, Campus de Irati- PR \\ joaogeo2013@gmail.com
}

\begin{abstract}
RESUMO
O Sistema de Faxinal é um sistema silvopastoril tradicional localizado em fragmentos de Mata de Araucária no estado do Paraná. Este sistema é composto por áreas de agricultura, pastagem nativa com criação de animais de forma extensiva através do criadouro comunitário e exploração das áreas de florestas. A ação dos animais e dos faxinalenses tem promovido uma fragmentação nas áreas de florestas neste ambiente. Este artigo tem como objetivo avaliar a relação entre a fragmentação da floresta, a disponibilidade de pasto e a compactação do solo em diferentes tipos de usos do solo (Mata de Araucária, Mata Secundária, Bosque e Pastagem) no Faxinal Paraná Anta Gorda em Prudentópolis PR. Foram instaladas 12 parcelas de $10 \times 10 \mathrm{~m}$ em cada tipo de uso, para mensurar as características de cada fragmento florestal, a luminosidade, a disponibilidade de pasto e a densidade e resistência do solo. Ao término da pesquisa conclui-se que a fragmentação da floresta potencializa a compactação. Os fragmentos com menor número de árvores indicaram maior volume de pasto e maior compactação do solo.
\end{abstract}

Palavras-chave: Criadouro comunitário. Raleamento da floresta. Luminosidade, disponibilidade de pasto. Degradação do solo.

\section{IS FOREST FRAGMENTATION AN INDICATOR OF SOIL COMPACTION IN THE FAXINAL SYSTEM?}

\section{ABSTRACT}

Faxinal is a traditional silvopastoral system, located in fragments of Araucaria Forest in the state of Paraná. This system consists of areas of agriculture, native pasture with extensive animal husbandry called "community breeding" and exploitation of forested areas. The action of animals and farmers has promoted fragmentation of forest areas in this environment. The aim of this paper was to evaluate the relationship between forest fragmentation, pasture availability and soil compaction in different types of land use (Araucaria Forest, Secondary Forest, Woodland and Pasture) at Faxinal Paraná Anta Gorda in Prudentópolis PR. We installed 12 plots of $10 \times 10 \mathrm{~m}$ for each type of use to measure the characteristics of each forest fragment, the light, the availability of pasture and the density and resistance of the soil. At the end of the research we concluded that forest fragmentation increases compaction. Fragments with fewer trees indicated higher pasture volume and greater soil compaction.

Keywords: Communal grazing land. Forest fragmentation. Luminosity, pasture. Soil degradation.

\section{INTRODUÇÃO}

As florestas são ecossistemas multifuncionais que fornecem diversos bens e serviços, incluindo bens intrínsecos, econômicos, valores culturais e estéticos essenciais para o desenvolvimento

$\begin{array}{lllll}\text { Caminhos de Geografia } \quad \text { Uberlândia } & \text { v. 20, n. } 72 & \text { Dez/2019 } & \text { p. 94-106 Página } 94\end{array}$


socioeconômico das comunidades adjacentes em uma determinada região (COSTA et al., 2017). No entanto, a ação das comunidades sobre esses ecossistemas têm sido um dos pontos chaves para a degradação ambiental (TESFAYE, 2017). As áreas de Sistema Faxinal que ainda existem em alguns fragmentos da Mata de Araucária na região sudeste do estado do Paraná é um exemplo dessas multifuncionalidades da floresta para com a vida das comunidades.

O Sistema Faxinal é uma forma de organização camponesa baseada na agricultura familiar, no uso coletivo dos recursos e na coletividade da mão-de-obra em atividades silvopastoril. Antoneli et. al. (2018) acrescentam que este sistema se assemelha as dehesas da Espanha e aos montados em Portugal, assim como o usi civici na Sardenha, Itália (VACCA, 2012), dentre outros sistemas silvopastoris espalhados por todo mundo.

O modelo de sistema faxinalense respalda-se na integração de três componentes: a) produção animal coletiva à solta, (sem restrição de propriedades) através dos criadouros comunitários denominados "áreas de criar"; b) produção agrícola - policultura alimentar de subsistência para consumo e comercialização denominados "áreas de plantar"; c) extrativismo florestal de baixo impacto - manejo de erva-mate, araucária e outras espécies nativas (PARANÁ, 1997).

A manutenção desta forma de organização camponesa tem encontrado diversas dificuldades nas últimas décadas. O avanço da agricultura mecanizada, a inserção de culturas rentáveis como cultivo do tabaco e soja e divergências entre os próprios faxinalenses em manter esse sistema, tem levado a redução das áreas de criadouro comunitário.

Cabe destacar que as áreas de criadouro comunitário são compostas por áreas de pastagens nativas entremeadas por fragmentos florestais. Os animais têm acesso livre em ambas as áreas, o que pode contribuir para a degradação do solo devido ao pisoteio intensivo dos animais em busca de alimento.

A degradação do solo pode ser definida como uma perda e/ou redução da qualidade do solo provocada por múltiplos processos que afetam a qualidade física, química e biológica e, como resultado, reduzir a produtividade, diversidade e qualidade das pastagens naturais (BILOTTA et al., 2007; KHORMALI et al., 2009). Os animais em pastejo podem desencadear um processo de degradação do solo que pode culminar com o abandono de pastagens. Exemplos de estudos de degradação do solo em pastagens são observados em diversas partes do globo terrestre por: Schnabel et al. (2006) região sudoeste da Espanha; Müller et al., (2004) em pastagens da Amazônia brasileira; Siyuan e Keith (2014) no norte do Tibete, Ayoubi et al. (2014) no oeste do Iran; Rocha Junior et al. (2017) na Mata Atlântica sudeste do Brasil; Gasanov et al. (2013) no noroeste do Mar Caspio; Donkor et al. (2002) na região de Alberta Canadá, dentre tantos outros.

Além da degradação do solo, os animais em pastejo exercem influência sobre a vegetação, principalmente em áreas de pastagens extensivas onde há um consorciamento entre pastagens e fragmentos de florestas. $O$ contato dos animais com as áreas de floresta promove um raleamento da vegetação (DIAS FILHO, 2006) dificultando a regeneração (ANTONELI e THOMAZ, 2011; NÚÑ̃E, et al., 2012), pois algumas espécies servem de alimento para os animais. Antoneli et al. (2019), observaram menor disponibilidade de pasto no período de inverno nas áreas de pastagens, o que pode ser atribuído as condições climáticas (ocorrência de geadas). Neste caso, se há menor disponibilidade de pasto, pode haver maior circulação dos animais em busca de alimentos tanto nas pastagens quanto nas florestas.

Os problemas ambientais podem se agravar quando não são utilizadas práticas conservacionistas como rodízio de pastagens, controle de animais, adição de fertilizantes, controle de ervas daninhas, dentre outros. Neste contexto, a falta de práticas conservacionista em áreas de Faxinais pode contribuir com a degradação do solo. O livre acesso dos animais pela área de criadouro comunitário associado a exploração da vegetação pelos faxinalenses promovem um raleamento e fragmentação das áreas de florestas (ANTONELI et al., 2019).

Este raleamento potencializa o atravessamento de luz no interior da floresta possibilitando o desenvolvimento das gramíneas nestes locais. Essa condição permite que os animais busquem alimentos nas áreas de floresta, intensificando o pisoteio, podendo levar à compactação do solo.

$\begin{array}{lllll}\text { Caminhos de Geografia } \quad \text { Uberlândia } & \text { v. 20, n. } 72 \quad \text { Dez/2019 } & \text { p. 94-106 Página } 95\end{array}$


Cabe destacar que a disponibilidade de luz desempenha um papel importante na diferenciação de nicho (VALLADARES e NIINEMETS, 2008).

Diante do exposto, esta pesquisa teve como objetivo relacionar o volume de forragem (pasto) com a compactação do solo em diferentes fragmentos florestais em áreas de faxinal. Partiu-se do pressuposto que a fragmentação da floresta potencializa o atravessamento de luminosidade no piso florestal aumentando a disponibilidade de forragem que, por conseguinte pode indicar um gradiente de compactação do solo.

O sistema de Faxinal foi utilizado como recorte espacial para esta pesquisa, por ser um sistema pouco conhecido no cenário cientifico. Para identificar os pontos de coleta nos diferentes tipos de fragmentos florestais no Faxinal, foram realizadas atividades de campo para identificar pontos de maior representatividade.

\section{MATERIAL E MÉTODO}

\section{Caracterização da área de estudos}

Atualmente na Região sudeste do estado do Paraná existe 28 faxinais (MARQUES, 2004) e deste total, 11 estão localizados no município de Prudentópolis PR. Dentre eles, está o Faxinal Paraná Anta Gorda que desponta como um dos mais preservados do município, mantendo as características originais (criadouro comunitário), (Figura 1).

Figura 1 - Localização da área de estudos.
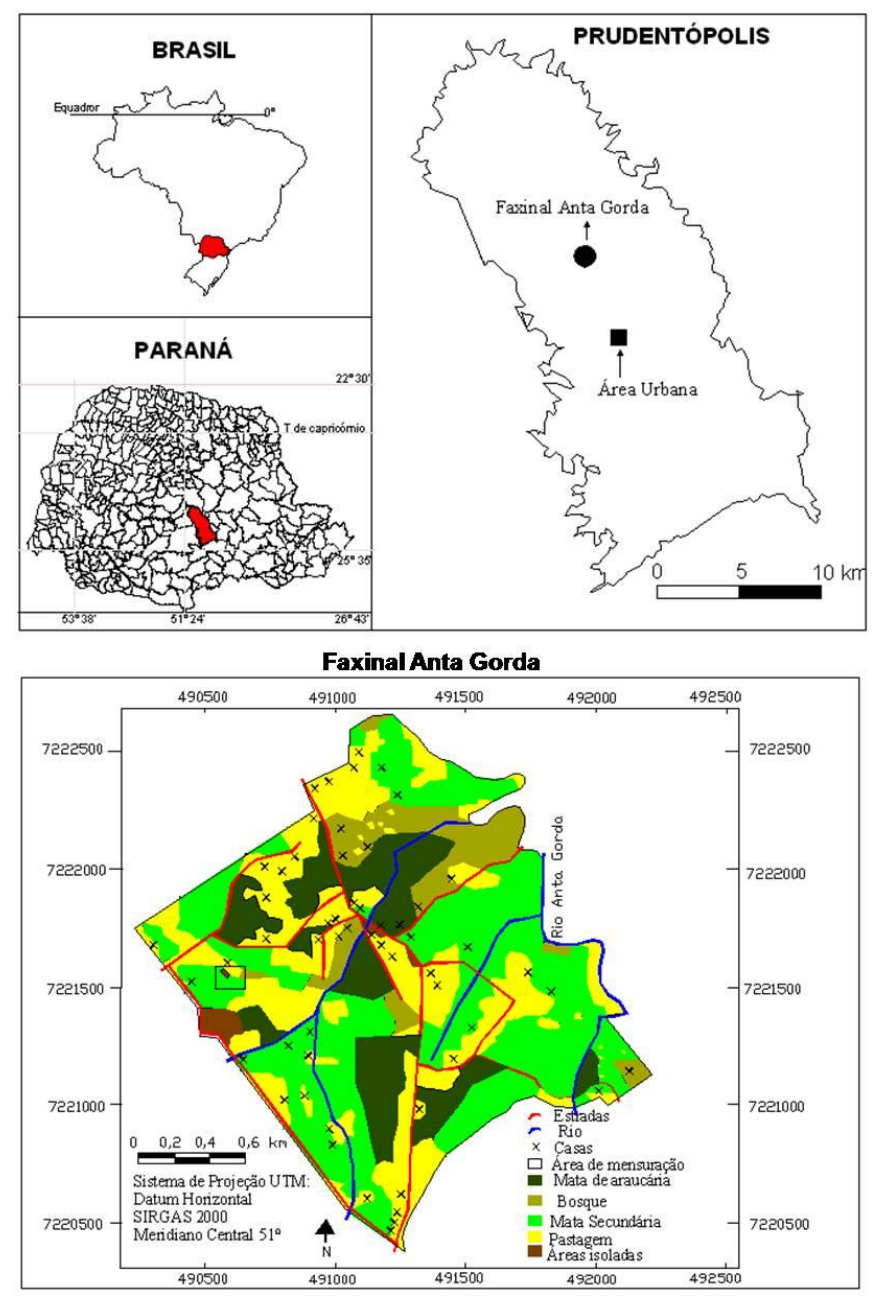

Fonte - Autores (2018). 
O Faxinal Paraná Anta Gorda possui uma área de 276.5 hectares, o qual é destinado ao criadouro comunitário e este é dividido em categorias menores. A área de Pastagem ocupa $36,4 \%$ do total, seguido da Mata Secundária com 34,7\%, já o Bosque e a Mata de Araucária ocupam 16,1\% e 11,4\% respectivamente. $O$ restante $(0,7 \%)$ compreende as residências, áreas agrícolas e as estradas. Cabe destacar que o percentual de pastagem $(36,4 \%)$ refere-se as áreas de pastagem do criadouro comunitário e dos potreiros (áreas particulares ou isoladas).

Há um total de 64 famílias neste Faxinal, com aproximadamente 240 pessoas, as quais utilizam a agricultura de subsistência com cultivo de milho, feijão, arroz dentre outros. Nas áreas mecanizadas é efetuado o cultivo de soja e tabaco.

Os faxinalenses também utilizam-se da criação extensiva de animais para sua sobrevivência, sendo que a criação de suínos se sobressai às demais, devido ao fácil processo de crescimento e engorda desses animais. Estes se alimentam de vários produtos que encontram dentro do criadouro comum, como raízes, frutos, pasto, dentre outros. Em um levantamento prévio (conversa com os faxinalenses), estimamos que em 2016 haviam no faxinal cerca de 90 bovinos, 60 equinos, 250 caprinos e 1500 suínos. Todos sendo criados soltos dentro do criadouro comunitário.

Para alcançar os objetivos propostos por esta pesquisa, partimos de um entendimento da dinâmica do Faxinal e como essa fragmentação pode interferir na manutenção e/ou desarticulação deste sistema (Figura 2).

Figura 2 - Fluxograma representativo da influência da fragmentação florestal em faxinais.

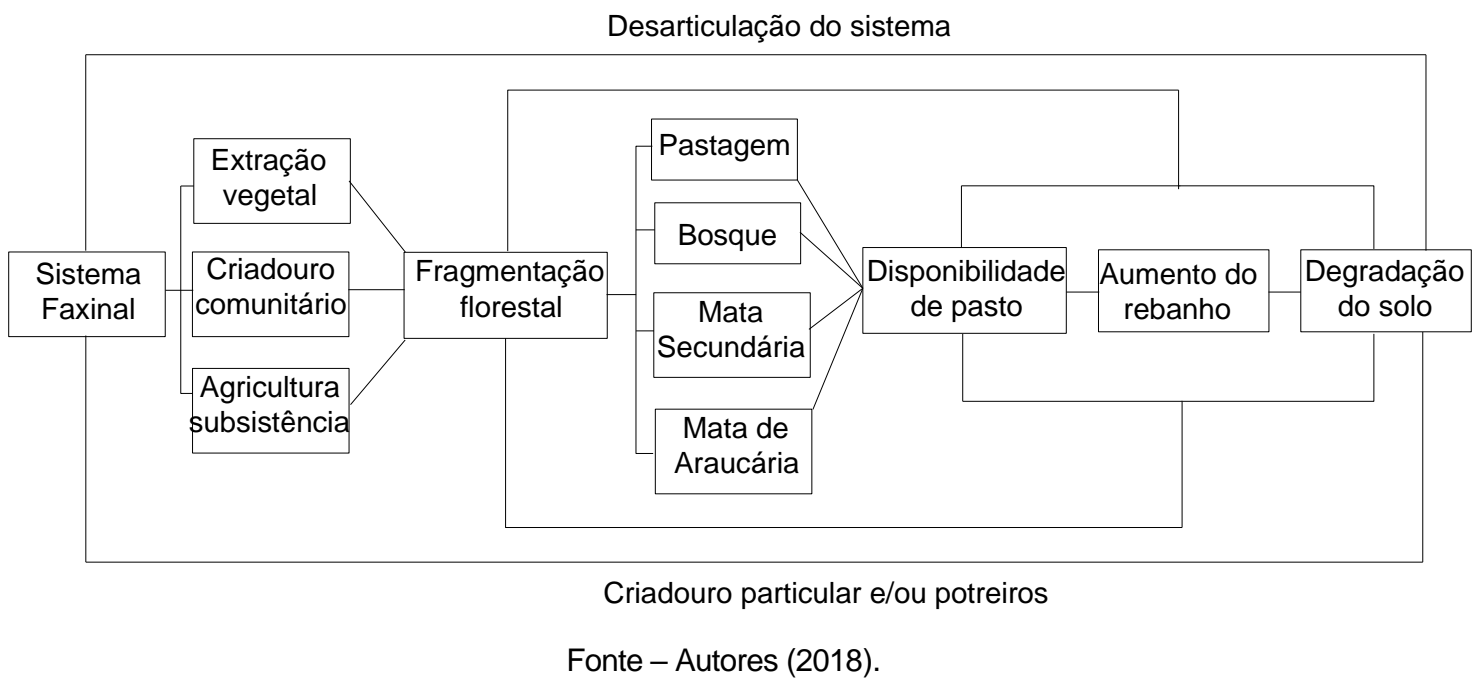

Para avaliar a influência da fragmentação da floresta na compactação do solo, foram realizadas atividades de campo para identificar a densidade de árvores por hectare, luminosidade no interior dos fragmentos florestais, volume de pastagens, densidade e resistência do solo. Todas essas variáveis foram mensuradas em um transecto partindo de áreas de pastagem que geralmente estão localizadas próximas as casas dos faxinalenses passando por áreas de Bosque, Mata Secundária e Mata de Araucária (Figura 3). Este transecto foi utilizado em uma área representativa do Faxinal com as características similares ao restante do faxinal.

A Mata de Araucária é uma floresta densa e apresenta três estratos bem definidos (dossel, sub bosque e herbáceas) com presença de Araucaria angostifolia; a Mata Secundária é uma floresta mais aberta com apenas dois estratos (dossel e sub bosque); o Bosque se caracteriza como uma vegetação espaça (totalmente aberta) e apenas com o dossel. Já a Pastagem indica algumas árvores esparsas.

\begin{tabular}{llllll}
\hline Caminhos de Geografia & Uberlândia & v. 20, n. 72 & Dez/2019 & p. 94-106 & Página 97
\end{tabular}


Figura 3 - Esquema representativo da fragmentação da floresta.

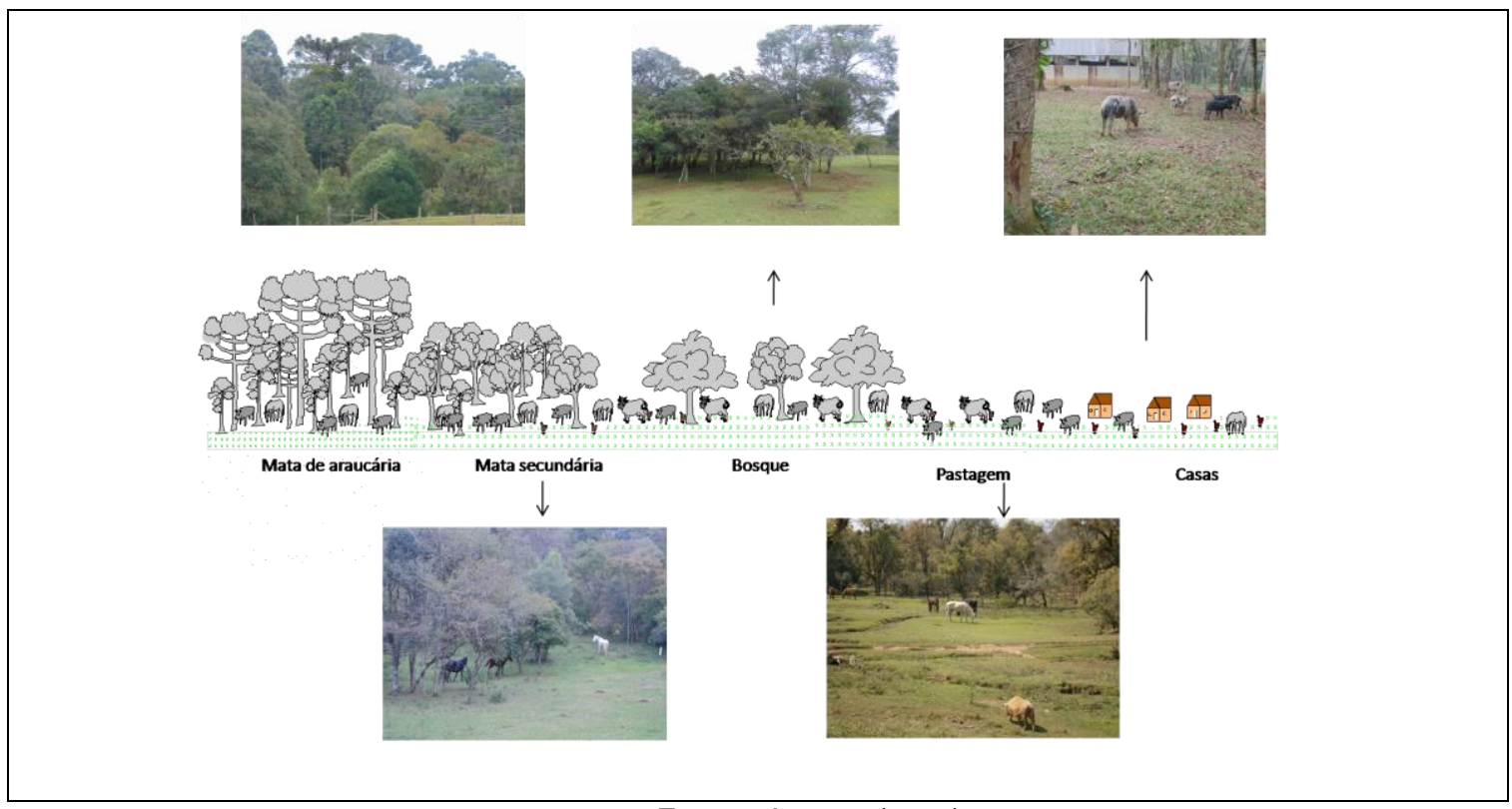

Fonte - Autores (2018).

\section{Procedimento de coleta dos dados}

Em cada fragmento florestal foi mensurada a densidade de árvore, Diâmetro da Altura do Peito- DAP, espécies, luminosidade, volume de pasto, resistência e densidade do solo. Para a mensuração dessas variáveis foram identificadas 12 parcelas de 10×10 metros em cada fragmento, totalizando 36 parcelas no total.

Em cada parcela foram realizadas 12 coletas de luminosidade no piso florestal, além do monitoramento na área de pastagem, totalizando 48 amostras em cada campanha de coleta. Foram realizadas quatro campanhas ao longo do ano de 2016, sendo uma campanha em cada estação do ano. Justificou-se as coletas ao longo das estações por observar que a mesma apresenta variação na deposição de serrapilheira (THOMAZ e ANTONELI, 2015), indicando variação no atravessamento de luz no piso florestal.

As coletas de luminosidade foram realizadas nas mesmas parcelas onde foram levantadas as características da estrutura da vegetação. Os 12 pontos de coleta foram distribuídos em forma de malha sobre a parcela e demarcados para que as coletas fossem realizadas sempre no mesmo local. As coletas foram realizadas entre às 13:00 e 14:00 horas. Para a mensuração da porcentagem de luminosidade no interior dos fragmentos florestais, foi utilizado um luximetro modelo LD-200. Os dados de intensidade de luz obtida na Pastagem (área aberta), foi considerada em torno de 95\%, a partir disso foram obtidos a porcentagem de luminosidade em cada fragmento florestal. As leituras de luminosidade foram realizadas à 1 metro de altura da superfície.

A disponibilidade de pastagem ao longo do ano foi mensurada através da instalação de 12 "gaiolas" (parcelas fechadas) de $1 \times 1 \mathrm{~m}^{2} \mathrm{em}$ cada tipo de uso, totalizando 48 gaiolas. Essas gaiolas foram instaladas no mês de dezembro de 2015 e retiradas em dezembro de 2016. Para avaliar o volume de pastagem de cada tipo de uso do solo, toda a gramínea disposta na superfície da parcela isolada do pastoreio foi totalmente cortada e levada ao laboratório para pesagem. Foi cortada também a gramínea total de 5 parcelas com pastoreio constante para saber qual a disponibilidade real de pasto em cada área e, pela diferença entre os valores foi possível estimar a quantidade de pasto disponível para os animais ao longo do ano.

A resistência do solo a penetração foi monitorada através da utilização de um penetrômetro de impacto o qual avalia a resistência do solo em perfil de $0-60 \mathrm{~cm}$ de profundidade. No entanto, utilizamos de 0 a $40 \mathrm{~cm}$ a profundidade, por observar que a influência se restringe apenas as

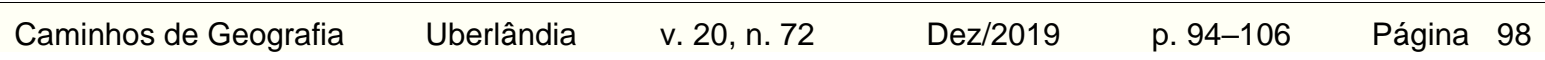


camadas superficiais do solo. Este aparelho de medida da resistência do solo é do tipo dinâmico, cuja penetração ocorre por impacto (STOLF et al., 2014).

Os dados referentes ao número de impactos e as respectivas profundidades de cada impacto foram transferidos para uma planilha Excel com Visual Basic Aplication (VBA), como linguagem de programação, ambas da Microsoft $\Theta$. Foram realizadas 12 repetições em cada tipo de uso do solo. Os pontos foram identificados de forma aleatória em cada área.

Para análise da densidade do solo foram abertas 12 trincheiras em cada área de forma aleatória. As trincheiras foram abertas a uma profundidade de até $40 \mathrm{~cm}$. As coletas no perfil da trincheira foram realizadas entre $0-10 \mathrm{~cm}, 10-20 \mathrm{~cm}$ 20-30 e $30-40 \mathrm{~cm}$. Foram coletadas três amostras (repetições) em cada profundidade.

Para análise da densidade aparente do solo foi utilizada a técnica de anel volumétrico (cilindro de metal) de $100 \mathrm{~cm}^{3}$, que foi introduzido no solo para preencher o volume total do anel. As amostras foram acondicionadas em pacotes plásticos e levadas ao laboratório para secagem a $105^{\circ} \mathrm{C}$ por 24 horas em estufa para a retirada da umidade. Após a secagem as amostras foram pesadas e aplicadas a equação, proposta pela Embrapa (1997).

$$
D_{s}=\frac{M_{s}}{V}
$$

Sendo:

$$
\begin{aligned}
& D_{s}=\text { Densidade do solo }\left(\mathrm{g} / \mathrm{cm}^{3}\right) \\
& M_{s}=\text { Massa seca }(\mathrm{g}) \\
& \mathrm{V}=\text { volume do anel }\left(\mathrm{cm}^{3}\right)
\end{aligned}
$$

Para análise dos dados foi utilizada estatística descritiva como a média, desvio padrão, máximo e mínimo, além da análise de variância (ANOVA) para comparar as variáveis entre os tipos de usos. Aplicou-se teste estatístico (Teste de Tukey) para comparar as mesmas variáveis em diferentes tipos de uso do solo. Para a representação dos dados utilizamos o software StatSoft $\AA^{\circ}$.

\section{RESULTADOS E DISCUSSÃO}

\section{ESTRUTURA DA FLORESTA}

Ao considerar que a formação florestal primária em áreas de Faxinais era a Floresta Ombrófila Mista (Mata de Araucária), constata-se a existência de fragmentos diferenciados de florestas nesta forma de uso e ocupação. Segundo (STRUMINSKI e STRACHULSKI, 2012) a interferência humana criou um mosaico de formações secundárias neste ambiente.

No Faxinal Paraná Anta Gorda, foi observado três estruturas de florestas sendo: Bosque, Mata Secundária e Mata de Araucária. Cabe destacar que a Mata de Araucária que nos referimos aqui é em decorrência da concentração de Araucaria angustifolia, pois a mesma apresenta distúrbios no seu interior, devido ao contado dos animais em pastejo. No entanto, a ação dos animais parece ser menor em relação aos demais tipos de fragmentos florestais, pois a mesma apresenta maior número de indivíduos, distribuídos em três estratos (dossel, sub bosque, e herbáceas) (Tabela 1).

Observou-se que há um gradiente de vegetação com características diferentes na estrutura dos fragmentos florestais. A Pastagem apresenta algumas árvores esparsas entremeadas às pastagens e sem substratos. Geralmente são árvores como o pinheiro do Paraná (Araucaria angustifolia) e a guabirobeira (Campomanesia xanthocarpa), pois essas espécies são frutíferas e podem ser incorporadas na alimentação dos animais.

As áreas de Bosque são totalmente abertas e com pouca presença de sub bosque $(10,6 \%)$. Predominando nessas áreas espécies como a guabirobeira (Campomanesia xanthocarpa), açoita cavalo (Luehea divaricata) e imbuia (Ocotea porosa), dentre outras com menor quantidade.

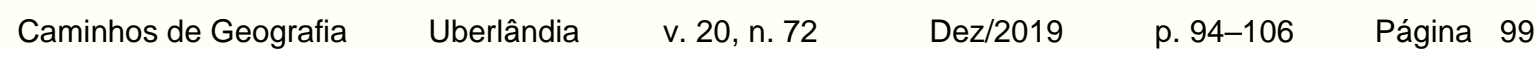


Tabela 1 - Características das árvores.

\begin{tabular}{ccccc}
\hline $\begin{array}{c}\text { Tipo de uso do } \\
\text { solo }\end{array}$ & $\begin{array}{c}\text { № total de } \\
\text { árvores }(\mathrm{a} / \mathrm{ha})\end{array}$ & $\begin{array}{c}\text { № de árvores no } \\
\text { dossel }(\mathrm{a} / \mathrm{ha})\end{array}$ & $\begin{array}{c}\text { № de árvores no } \\
\text { sub bosque }(\mathrm{a} / \mathrm{ha})\end{array}$ & $\begin{array}{c}\text { DAP médio } \\
(\mathrm{cm})\end{array}$ \\
\hline Pastagem & $15 \pm 5$ & $15 \pm 5$ & - & $70 \pm 21$ \\
\hline Bosque & $132 \pm 28$ & $118 \pm 21$ & $14 \pm 7$ & $95,8 \pm 37$ \\
\hline M. Secundária & $375 \pm 37$ & $287 \pm 20$ & $88 \pm 17$ & $65 \pm 61$ \\
\hline M. Araucária & $610 \pm 71$ & $386 \pm 40$ & $224 \pm 31$ & $81 \pm 97$
\end{tabular}

Nota: Os valores referem-se a média das 12 parcelas em cada tipo de uso do solo. Fonte - Autores (2018).

O sub bosque em sua maioria era composto por murta (Blepharocalyx salicifolius). Essa espécie não é consumida pelos animais em seu estágio de germinação e brotamento, o que favorece sua propagação no sub bosque. O maior número de árvores que compõem o dossel contribui para o aumento no diâmetro médio das árvores.

A Mata Secundária apresenta dois estratos de vegetação sendo o dossel com aproximadamente $76,5 \%$ das árvores e $23,5 \%$ de sub bosque. Dentre as espécies, encontramos diversos tipos de canelas da família das Lauraceas como: canela guaica (Ocotea Puberula), canela preta (Ocotea corymbosa), imbuia (Ocotea porosa) dentre outras. Já no sub bosque foi observado um predomínio de guaçatunga-vermelha (Casearia obliqua), corroborando com dados observado por Albuquerque et al. (2011). Outras espécies também se destacam como a murta (Blepharocalyx salicifolius), guaçatunga (Casearia decandra), erva-mate (llex paraguariensis), dentre outras.

Já a Mata de Araucária indicou maior número de árvores por hectare (média de 610 a/ha) distribuídas em três estratos (dossel, sub bosque e herbáceas). Deste total, 63,2\% das árvores compõe o dossel e $36,7 \%$ o sub bosque. O DAP médio foi de $81 \mathrm{~cm}$ nesta categoria, sendo inferior apenas ao Bosque. Neste caso, os estratos inferiores da floresta contribuem para a redução dessa média. Cabe destacar que as herbáceas inferiores a $10 \mathrm{~cm}$ de diâmetro não foram mensuradas neste total de árvores.

As espécies mais encontradas nesse fragmento de floresta são: pinheiro do Paraná (Araucaria angustifolia), imbuia (Ocotea porosa), peroba, (Aspidosperma polyneuron), cedro (Cedrela fissilis), guacatunga (Casearia decandra), ambos no dossel. No sub bosque encontramos cafezeiro-do-mato (Casearia silvestris), guaçatunga (Casearia decandra), erva-mate (Ilex paraguariensis), dentre outras.

A variabilidade de espécies, intensidade, estrutura, estágio de desenvolvimento são atributos florestais que podem contribuir para o atravessamento de luz e água no interior da floresta (CLINTON, 2003; LIMA e GANDOLFI, 2009).

\section{LUMINOSIDADE E DISPONIBILIDADE DE PASTO NO INTERIOR DA FLORESTA}

A quantidade de luz que chega ao piso florestal torna-se um importante fator abiótico que influencia no aumento da riqueza de espécies vegetais (AAVIK et al., 2008), na umidade do solo (CLINTON, 2003), dentre outros fatores. Em florestas onde houve raleamento das árvores, a intensidade da radiação solar que chegou ao piso florestal foi maior. Esta condição pode ser atribuída ao grau de mudança do dossel e das espécies de árvores presentes em cada fragmento florestal (WATLING e ORROCK, 2010).

No caso das florestas que compõem o Faxinal, a ação dos animais e o corte da madeira pelos faxinalenses promoveram um raleamento da floresta indicando variação na distribuição de luminosidade no interior da floresta (Figura 4A). Pavlovic et al. (2006), corroboram com esta questão ao afirmar que o desempenho, composição e diversidade de plantas alteram a resposta do atravessamento da luz no interior da floresta.

A Pastagem por apresentar menor número de árvores por hectare $(15 \mathrm{a} / \mathrm{ha})$ indicou luminosidade acima de $95 \%$. Este parâmetro serviu para avaliar o percentual de luminosidade nos diferentes tipos de usos. Gossner (2009) corrobora com essa questão ao observar que a maior intensidade de luz perto do solo em locais onde o dossel era esparso, resultou em maior diversidade de plantas. Neste

Caminhos de Geografia Uberlândia $\quad$ v. 20, n. $72 \quad$ Dez/2019 $\quad$ p. 94-106 Página 100


contexto a luminosidade pode ter potencializado o volume do pasto nos diferentes usos do solo (Figura 4B)

Figura 4 - A) distribuição da luminosidade. B) disponibilidade de pasto.
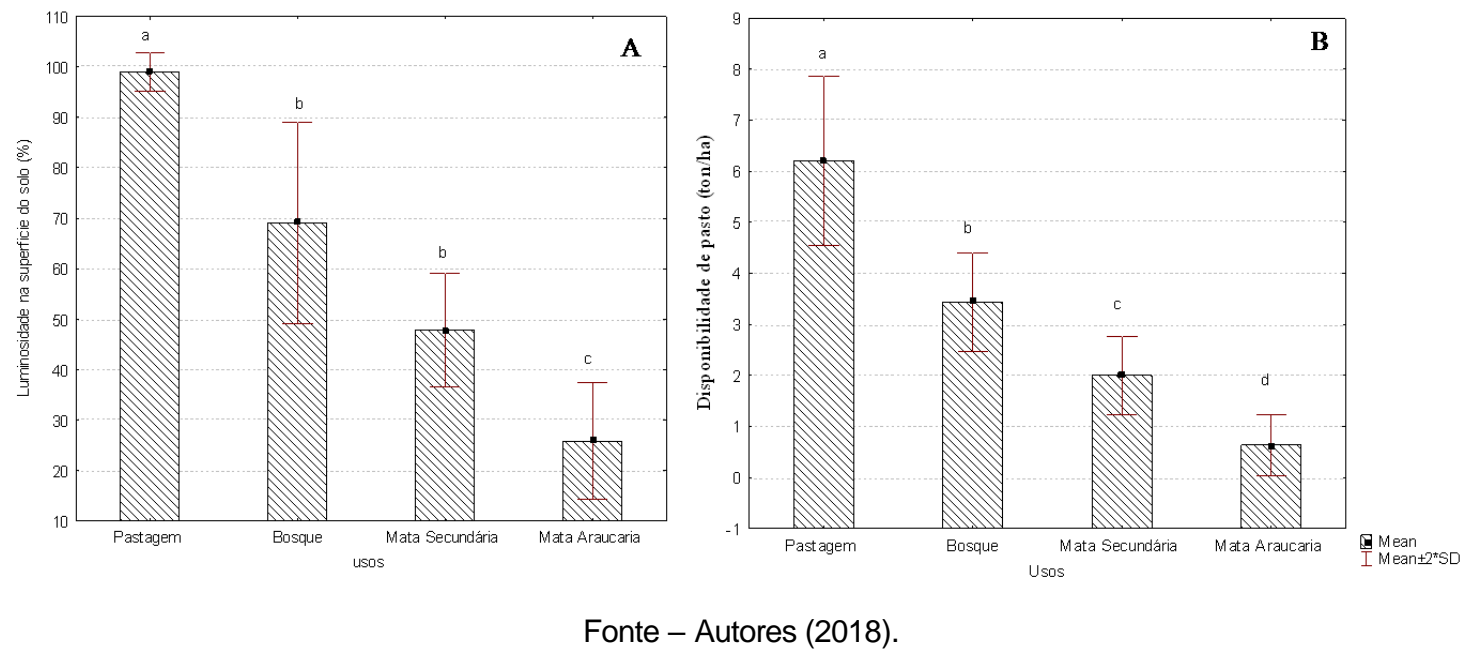

$\mathrm{Na}$ área de Bosque, a luminosidade média foi de $70 \%$, ou seja, a menor quantidade de árvores neste fragmento florestal indicou maior atravessamento de luz dentre as áreas florestadas. Cabe considerar, que, quando há raleamento da floresta promovido pelo próprio faxinalense (roça e desbaste do interior da floresta), há uma seleção de espécies que acabam sendo preservadas.

Dentre essas espécies preservadas destacam-se a guabirobeira, (Campomanesia xanthocarpa), pitangueira, (Eugenia uniflora) pinheiro do Paraná (Araucaria angustifolia), dentre outras, pois essas são árvores frutíferas. A preservação de espécies frutíferas em áreas de Faxinais é uma prática recorrente (apesar de não ser padrão) entre os faxinalenses pois esses frutos podem ser incorporados na alimentação dos animais. Parte dessas espécies são caducifólias e perdem suas folhas nos meses mais frios e como não há sub bosque, a luz pode chegar com mais facilidade no piso florestal.

A Mata Secundária apresentou maior número de indivíduos em relação ao Bosque o qual pode ter contribuído com o menor atravessamento de luz no piso florestal. Apesar da variação entre o número de indivíduos, não houve variação estatística do atravessamento de luz entre esses dois fragmentos a nível de $5 \%$ de significância pelo teste de Tukey.

A menor porcentagem de luminosidade foi observada na Mata de Araucária (27\%), a qual está associada ao número de indivíduos (610 a/ha) e a estrutura da floresta que apresenta três estratos bem definidos (dossel, sub bosque e herbáceas). Essa estrutura da floresta contribui para a redistribuição da luz entre esses três estratos, reduzindo a quantidade de luz que chega ao piso florestal (RIGUEIRA et al., 2012)

Quando relacionada, a densidade de árvores com a luminosidade dentre todos os fragmentos florestais estudados, observamos alta correlação $(r=0,9023)$, onde a maior quantidade de árvores correspondeu com a menor luminosidade e vice versa.

A diferença nas condições de luminosidade reflete na existência de distintos ambientes dentro da floresta que são explorados por grupos de espécies com diferentes capacidades de sobrevivência nesses locais (GANDOLFI, 2003). No caso das florestas de Faxinais com pastoreio extensivo, a maior luminosidade tem pouca influência na reestruturação da floresta, devido a ação dos animais e dos faxinalenses que dificultam a regeneração da floresta. Neste caso a luminosidade pode interferir na disponibilidade de pasto dentro desses fragmentos florestais.

A Pastagem indicou disponibilidade de pasto em torno de 6,2 ton/ha/ano, já as áreas com florestas indicaram um gradiente de pastagem decrescente partindo do Bosque até a Mata de Araucária (3,4 ton/ha/ano, 2,0 ton/ha/ano e 0,85 ton/ha/ano, respectivamente) havendo variação significativa entre os três fragmentos florestais a nível de $5 \%$ pelo teste de Tukey. A variação da disponibilidade de

Caminhos de Geografia Uberlândia $\quad$ v. 20, n. $72 \quad$ Dez/2019 $\quad$ p. 94-106 Página 101


pasto significa maior intensidade do pisoteio dos animais que pode refletir na variação das condições físicas do solo nesses ambientes (ANTONELI et al., 2019).

\section{RESISTÊNCIA E DENSIDADE DO SOLO}

A criação de animais de modo extensivo tem causado alguns problemas ambientais que podem interferir nas condições físicas do solo (RADFORD et al., 2008; SANTOS et al., 2010), principalmente por não haver práticas conservacionistas e regulamentação sobre as taxas de lotação animal. Todos esses fatores estão levando a sérios problemas de degradação do solo e da pastagem em muitas escalas (MARTHA JÚNIOR e CORSI, 2001).

A variação da disponibilidade de forragem, nos diferentes tipos de uso em áreas de Faxinais tem contribuído com a variação das condições físicas do solo. Antoneli et al. (2019) observaram que o gradiente de disponibilidade de pasto em áreas de Faxinais indicou um gradiente de condições físicas do solo. Este gradiente também foi observado nessa pesquisa, no qual há uma variação significativa da resistência e densidade do solo entre os tipos de usos. Tornou-se consenso entre os pesquisadores que a ação dos animais nas condições físicas do solo se restringe as primeiras camadas do solo (ARAÚJO et. al., 2007; PULIDO et al., 2016). Esta questão se confirma nesta pesquisa (Figura 5), onde a influência dos animais na compactação do solo foi até $20 \mathrm{~cm}$ de profundidade.

Figura 5 - Variação das condições físicas do solo. A) resistência do solo; B) densidade do solo.

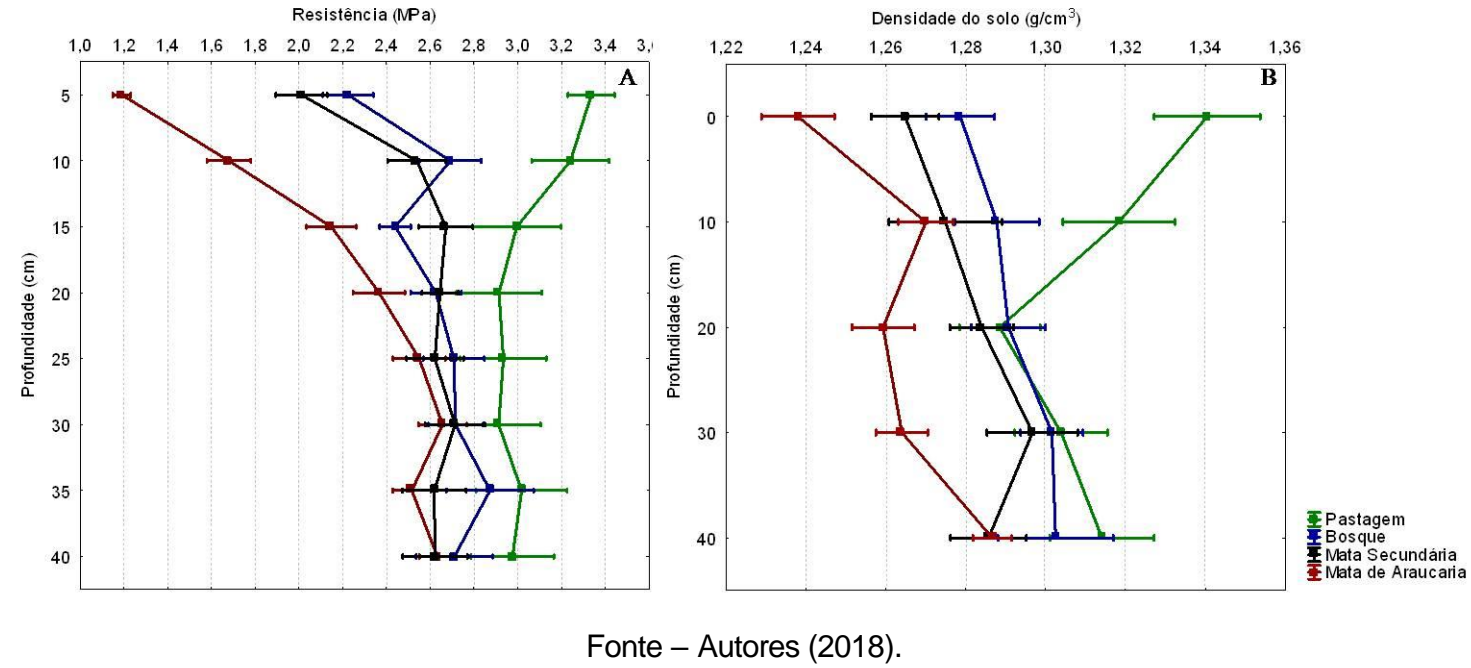

Os diferentes tipos de usos indicaram variação na resistência e densidade do solo nas primeiras camadas $(0$ a $20 \mathrm{~cm}$ de profundidade). A partir dessa camada $(20 \mathrm{~cm})$ há certa homogeneidade nos dados, exceto a densidade do solo na Mata de Araucária que indicou variação significativa nas profundidades acima de $20 \mathrm{~cm}$ de profundidade. Observamos um gradiente de compactação do solo, partindo da Mata de Araucária (menores valores) para a Pastagem (maiores valores). No entanto, a área de Bosque e Mata Secundária indicaram valores próximos, não apresentando variação significativa a nível de $5 \%$ do teste de Tukey.

As primeiras camadas de solo na Pastagem indicaram os maiores índices de compactação, com uma resistência média de $3,2 \mathrm{MPa}$ e densidade em torno de $1,32 \mathrm{~g} / \mathrm{cm}^{3}$. Esses valores tornam-se impeditivos para o desenvolvimento radicular das plantas (WEIL et al., 1993; MENEZES, 2008; DREWRY et al., 2008) o que pode contribuir para o aumento da degradação dessas pastagens.

A melhor qualidade do solo na Mata de Araucária pode ser atribuída também as condições florestais como deposição de serrapilheira, aumento de matéria orgânica e umidade do solo. Esses condicionantes contribuem para maior agregação e porosidade do solo, que interferem na resistência e densidade do mesmo. 
Os dados médios das variáveis mesuradas foram inseridos em um quadro síntese (Figura 6), no qual os maiores valores atribuímos cem por centro (100\%) e deste total, calculamos o percentual de variação de cada tipo de uso.

Figura 6 - Média de cada variável nos diferentes usos.

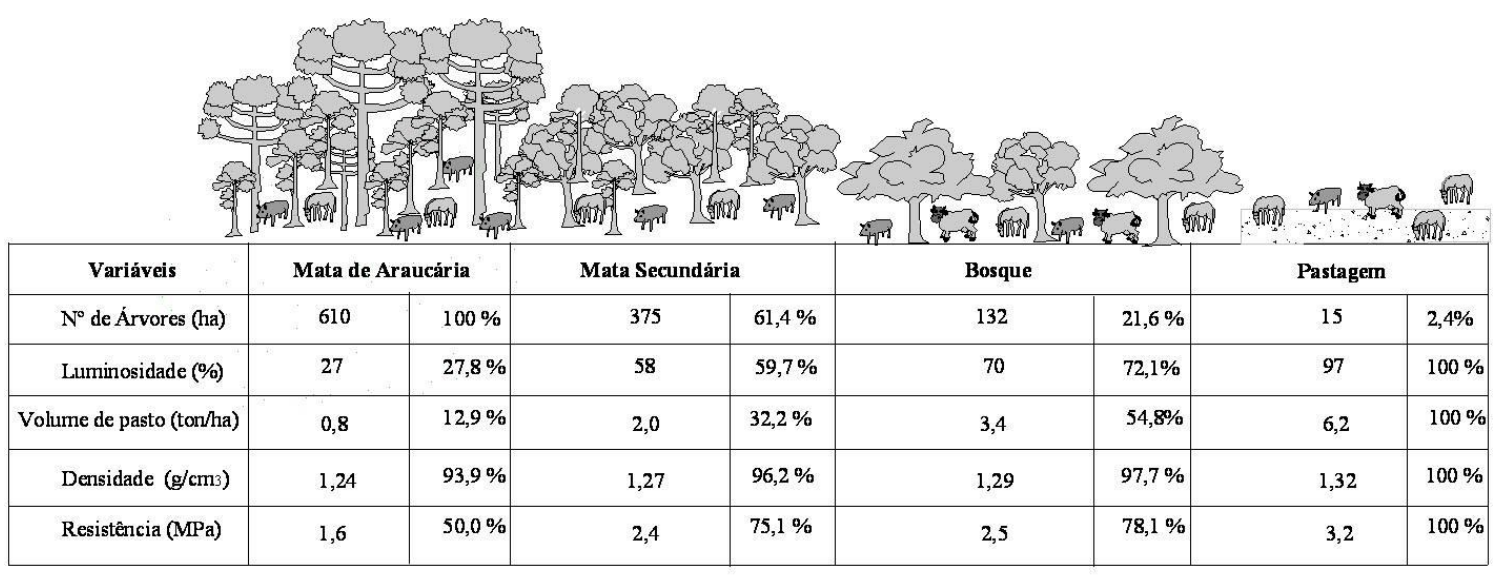

Fonte - Autores (2018)

A menor disponibilidade de pasto na Mata de Araucária pode desencadear uma sequência lógica de processos que culmina com as melhores condições físicas do solo. Nesta sequência tem-se, uma floresta em melhores condições ambientais com estratos bem definidos, o que reduz 0 atravessamento de luz reduzindo o volume de pastagem neste fragmento florestal. Esta condição culmina com menor pressão dos animais em pastejo.

A menor intensidade de pastoreio pode contribuir com a composição das comunidades florestais, proporcionando florestas mais densas, apesar dessa sequência lógica continuar sendo um desafio de escalas (LANDSBERG et al., 2002). No entanto, haverá uma redução da disponibilidade de pasto, culminando com maior pressão dos animais sobre as áreas de pastagens já existentes. A medida que a vegetação vai sofrendo raleamento aumenta o atravessamento de luz contribuindo com maior disponibilidade de pasto (MONTGOMERY e CHAZDON, 2002). Esta sequência culmina com a maior compactação do solo devido a maior pressão dos animais em pastejo.

\section{CONSIDERAÇÕES FINAIS}

Ao término desse trabalho conclui-se que a fragmentação da floresta contribui de forma significativa na compactação do solo, pois apresenta gradiente de distribuição de indivíduos que interfere no atravessamento de luz no piso florestal, o qual contribui com a disponibilidade de pasto. O maior volume de pasto pode contribuir no aumento da concentração de animais em pastejo nesses ambientes, potencializando a degradação do solo, além de contribuir para o aumento da fragmentação da floresta, tornando se um ciclo vicioso. Portanto a fragmentação da floresta em áreas de Faxinais pode ser um indicador de compactação do solo.

Há necessidade de estudos mais aprofundados em relação a fragmentação da floresta em áreas de Faxinais. Esta questão precisa ser analisada por diferentes prismas, por apresentar aspectos positivos e negativos. Dentre os aspectos positivos, dessa fragmentação, observa-se que o aumento das áreas de pastagens pode interferir na redistribuição da pressão dos animais sobre as pastagens já existentes. Este aumento pode significar ampliação no número de rebanho e melhoria na qualidade dos animais em pastejo. Já nos aspectos negativos, a fragmentação da floresta pode levar a perda e/ou redução da biodiversidade das áreas de Faxinais e aumento da degradação do solo. Estes problemas ambientais, podem contribuir com a desarticulação desse sistema, tornando-se inviável do ponto de vista ambiental e socioeconômico.

Caminhos de Geografia Uberlândia $\quad$ v. 20, n. $72 \quad$ Dez/2019 $\quad$ p. 94-106 Página 103


Portanto, apesar dos problemas ambientais que os faxinais enfrentam, este sistema ainda é uma forma de manutenção de algumas famílias no campo. A criação de animais de forma extensiva nos criadouros comunitários é uma maneira encontrada pelos agricultores que não dispõem de terras suficiente para criar seus rebanhos. Com isso, esses animais são incorporados na alimentação dessas famílias como a carne, leite e seus derivados. Destaca-se que o excedente é comercializado, aumentando assim a renda familiar.

\section{REFERÊNCIAS}

AAVIK T., JOGAR U., LIIRA J., TULVA I. \& ZOBEL M. Plant diversity in a calcareous wooded meadow - the significance of management continuity. Journal Vegetation of Science, v. 19: 475-484. 2008. https://doi.org/10.3170/2008-8-18380

ALBUQUERQUE, J. M. de; WATZLAWICK, L. F.; MESQUITA, N. S. de. Efeitos do uso em sistema faxinal na florística e estrutura em duas áreas da Floresta Ombrófila Mista no Munícipio de Rebouças, PR. Ciência Florestal, Santa Maria, v. 21, n. 2, p. 323-334, abr.-jun. 2011. https://doi.org/10.5902/198050983236

ANTONELI , V.; THOMAZ, E. L.; BEDNARZ, J. A. The faxinal system: forest fragmentation and soil degradation on the communal grazing land. Singapore Journal of Tropical Geography, v.40, p 3449. 2019. https://doi.org/10.1111/sitg.12258

ANTONELI, V. E THOMAZ, E. L. Produção de serrapilheira em um fragmento de Floresta Ombrófila Mista com sistema de faxinal. Sociedade \& Natureza. Uberlândia, ano 24 n. 3, 489-504, set/dez. 2012. https://doi.org/10.1590/S1982-45132012000300009

ARAÚJO, R.; GOEDERT, W. J.; LACERDA, M. P.C. Qualidade de um solo sob diferentes usos e sob cerrado nativo. Revista Brasileira de Ciência do Solo, v. 31, n. 5, p. 1099-1108, 2007. https://doi.org/10.1590/S0100-06832007000500025

AYOUBI, S., EMAMI, N., GHAFFARI, N.; HONARJOO, N.; KANWAR L. SAHRAWAT, K.L. Pasture degradation effects on soil quality indicators at different hillslope positions in a semiarid region of western Iran. Environmental Earth Sciences, v. 71, n. 375. 2014. https://doi.org/10.1007/s12665$\underline{013-2440-x}$

BILOTTA, G.S, BRAZIER, R.E, HAYGARTH, P.M. The impacts of grazing animals on the quality of soils, vegetation, and surface waters in intensively managed grasslands. Advances in Agronomy, v, 94, p. 237-280. 2007. https://doi.org/10.1016/S0065-2113(06)94006-1

CLINTON, B. D. Light, temperature, and soil moisture responses to elevation, evergreen understorey, and small canopy gaps in the southern Appalachians. Forest Ecology and Management, v. 186, n. 1-3, p. 243-255, 2003. https://doi.org/10.1016/S0378-1127(03)00277-9

COSTA. S, CASANOVA C, SOUSA C, LEE P. What Does Conservation Mean for Women? The Case of the Cantanhez Forest National Park. Consevation \&. Society, v.15, n.2, p. 168-178. 2017.

https://doi.org/10.4103/cs.cs 1491

DIAS-FILHO, M. B. Sistemas silvipastoris na recuperação de pastagens degradadas. Embrapa Amazônia Oriental-Documentos (INFOTECA-E), 2006.

DONKOR, N.T.; GEDIR, J.V.; HUDSON, R.J.; BORK, E.W.; CHANASYK, D.S.; NAETH, M.A. Impacts of grazing systems on soil compaction and pasture production in Alberta.Canadian Journal of Soil Science, v. 82, p. 1-8. 2002. https://doi.org/10.4141/S01-008

DREWRY, J.J., CAMERON, K.C.; BUCHAN, G.D. Pasture yield and soil physical property responses to soil compaction from treading and grazing-review Australian Journal of Soil Research, v.46, n.3, p.237 - 256. 2008. https://doi.org/10.1071/SR07125

EMBRAPA - Empresa Brasileira de Pesquisa Agropecuária. Manual de Métodos de Análise de Solo. $2^{\underline{a}}$ ed. Centro Nacional de Pesquisa de Solos, Rio de Janeiro. 1997.

PARANÁ (Estado). Decreto Estadual no 3.446/97. 1997. 
GANDOLFI, S. Regimes de luz em florestas estacionais semideciduais e suas possíveis consequências. In: SALES, V. C. C. (Org.). Ecossistemas brasileiros: manejo e conservação. Fortaleza: Expressão, p. 305-311. 2003.

GASANOV. G. N.; USMANOV, R. Z.; MAGOMEDOV, N. R.; AITEMIROV, A. A.; GAMIDOV, I. R.; ADZHIEV, A. M. Prevention of Soil Degradation and Restoration of theProductivity of Natural Pastures in the Northwestern Caspian Sea Region. Arid Ecosystems, v. 19, n. 1 (54), p. 53-58. 2013. https://doi.org/10.1134/S2079096113010095

GOSSNER, M.M. Light intensity affects spatial distribution of Heteroptera in deciduous forests. European Journal of Entomology, v.106, p. 241-252, 2009. https://doi.org/10.14411/eje.2009.032

KHORMALI, F.; AJAMI, M.; AYOUBI, S.; SRINIVASARAO, C.; WANI, S. P. Role of deforestation and hillslope position on soil quality attributes of loess-derived soils in Golestan province. Iran.

Agriculture Ecosystems Environment, v.134, p.178-189. 2009.

https://doi.org/10.1016/j.agee.2009.06.017

LANDSBERG, J.; JAMES, C. D.; MACONOCHIE, J.; NICHOLLS, A. O.; STOL, J.; TYNAN, R. Scale-related effects of grazing on native plant communities in an arid rangeland region of South Australia. Journal of Applied Ecology, v. 39, p. 427-444. 2002. https://doi.org/10.1046/j.13652664.2002.00719.x

LIMA, R. A. F.; GANDOLFI, S. Structure of the herb stratum under different light regimes in the Submontane Atlantic Rain Forest Brazil. Journal of Biology v. 69, n. 2, p.289-296. 2009

MARQUES C.L.G. Levantamento preliminar sobre o sistema faxinal no estado do Paraná. Relatório de Consultoria Técnica/IAP. Guarapuava. 2004.

MARTHA JÚNIOR, G. B.; CORSI, M. Pastagens no Brasil: situação atual e perspectivas. Preços Agrícolas, Florianópolis, v. 171, p. 3-6, 2001.

MENEZES, CEG. Integridade de paisagem, manejo e atributos do solo no Médio Vale do Paraíba do Sul, Pinheiral-RJ. Tese (Doutorado em Agronomia em Ciência do Solo) - Universidade Federal Rural do Rio de Janeiro, Seropédica. 2008.164 p.

MONTGOMERY, R. A.; CHAZDON, R. L. Light gradient partitioning by tropical tree seedlings in the absence of canopy gaps. Oecologia, Berlin, v. 131, p. 165-174, 2002. https://doi.org/10.1007/s00442$\underline{002-0872-1}$

MÜLLER, M. M. L.; GUIMARÃES. M. F.; DESJARDINS, T.; MITJA, D. The relationship between pasture degradation and soil properties in the Brazilian amazon: a case study. Agriculture, Ecosystems \& Environment, v. 103, (2), p. 279-288. 2004. https://doi.org/10.1016/j.agee.2003.12.003

NÚÑEZ, V.; HERNANDO, A.; VELÁZQUEZ, R.; TEJERA, R. Livestock management in Natura 2000: A case study in a Quercus pyrenaica neglected coppice forest. Journal for Nature Conservation, v. 20, I. 1, p. 1-9. 2012. https://doi.org/10.1016/i.jnc.2011.07.001

PAVLOVIC N.B., GRUNDEL R. \& SLUIS W. Groundlayer vegetation gradients across oak woodland canopy gaps. The Journal of the Torrey Botanical Society, v.133, p. 225-239. 2006. https://doi.org/10.3159/1095-5674(2006)133[225:GVGAOW]2.0.CO;2

PULIDO, M., SCHNABEL, S., LAVADO CONTADOR, J.F., LOZANO-PARRA, J., GONZÁLEZ, F. The impact of heavy grazing on soil quality and pasture production in rangelands of SW Spain. Land Degradation \& Development. 2016. https://doi.org/10.1002/ldr.2501

RADFORD, B.J., YULE, D.F., BRAUNACK, M., PLAYFORD, C., Effects of grazing sorghum stubble on soil physical properties and subsequent crop performance. American Journal of Agricultural and Biological Sciences, v.3, n. 4, p.734-742. 2008. https://doi.org/10.3844/ajabssp.2008.734.742

RIGUEIRA, D. M. G.; MOLINARI, A. L. M.; MARIANO, D. L. S.; REIS, R. M.; PORTUGAL, A. B., SANTANA, N. de S.; SANTOS, R. A. dos. Influência da distância da borda e do adensamento foliar sobre a abundância de plantas pioneiras em um fragmento de floresta tropical submontana na Estação Ecológica de Wenceslau Guimarães (Bahia, Brasil). Acta Botanica Brasilica, 26(1), 197202. 2012. https://doi.org/10.1590/S0102-33062012000100019 
ROCHA JUNIOR, P. R. da.;ANDRADE, F. V.; SÁ MENDONÇA, E. de.; DONAGEMMA, G. K.; FERNANDES, R. B. A.;BHATTHARAI, R.; KALITA, P. K. Soil, water, and nutrient losses from management alternatives for degraded pasture in Brazilian Atlantic Rainforest biome. Science of The Total Environment, v. 583, n.1, p. 53-63. 2017. https://doi.org/10.1016/i.scitotenv.2016.12.187

SANTOS, J. T.; ANDRADE, A. P. de; FRANÇA da SILVA, I. de; SOARES da SILVA, D.; SANTOS, E. M. GOMES da SILVA, A. P. Atributos físicos e químicos do solo de Áreas sob Pastejo na Micro Região do Brejo Paraibano. Ciência Rural, v. 40, n. 12. 2010. https://doi.org/10.1590/S010384782010001200008

SCHNABEL, S, LAVADO CONTADOR, JF, GOMEZ GUTIERREZ, A, LAGAR TIMON, D. La degradacion del suelo en las dehesas de Extremadura. In Gestión ambiental Del ecosistema dehesa en la Peninsula Ibérica, Espejo Diaz, M, Martin Bellido, M, Matos, C, Mesias Diaz, FJ (eds). Junta de Extremadura: Merida; 63-71. 2006.

SIYUAN, H.; KEITH R. Impact of Meadow Degradation on Soil Water Status and Pasture Management-A Case Study in Tibet. Land Degradation \& Development, v. 26, I. 5. 2014. https://doi.org/10.1002/ldr.2358

STOLF, R.; et. al. Penetrômetro de impacto Stolf - Programa Computacional de dados em EXCELVBA. Revista Brasileira de Ciência do Solo. v.38 n.3 Viçosa 2014. https://doi.org/10.1590/S010006832014000300009

STRUMINSKI, E.; STRACHULSKI, J. Uma revisão de conceitos sobre florestas em faxinais com base em uma abordagem fitogeográfica. Terr@Plural, Ponta Grossa, v.6, n.1, p. 55-77, jan./jun. 2012. https://doi.org/10.5212/TerraPlural.v.6l1.0004

TESFAYE, S.S. Assessment of Local Community Perception of and Attitude Towards Participatory Forest Management (PFM) System and Its Implications for Sustainablity of Forest Condition and Livelihoods: The Case of Chilimo-Gaji Forest in Dendi District, West Shewa Zone, Oromia, Ethiopia. Journal of Earth Science \& Climatic Change, v. 8, n.382, p. 1- 10. 2017.

THOMAZ, E. L. Sistema Faxinal: pesquisa na UNICENTRO e perspectivas de estudos ambientais. Terra Plural, v.5, n.2, p.199-212. 2011. https://doi.org/10.5212/TerraPlural.v.5i2.0004

THOMAZ, E. L.: ANTONELI, V. Rain interception in a secondary fragment of Araucaria Forest with faxinal, Guarapuava-PR. CERNE, v. 21 n. 3, p. 363-369. 2015.

https://doi.org/10.1590/01047760201521031736

VACCA A. Comland Field trip in Sardinia, Italy. Field trip guide. Department of Chemical and Geological Sciences, University of Gagliari. 2012. 57 p.

VALLADARES, F.; NIINEMETS, Ü. Shade tolerance, a key plant feature of complex nature and consequences. Annual Review of Ecology, Evolution, and Systematics, v. 39, p237-57. 2008. https://doi.org/10.1146/annurev.ecolsys.39.110707.173506

WATLING, J.I.: ORROCK, J.L. Measuring edge contrast using biotic criteria helps define edge effects on the density of an invasive plant. Landscape Ecology 25: 69-78. 2010. https://doi.org/10.1007/s10980-009-9416-y

WEIL, R. R.; LOWELL, K.A.; SHADE, H. M. Effects of intensity of agronomic practices on a soil ecosystem. American Journal of Alternative Agriculture, v. 8, n. 01, p. 5-14, 1993. https://doi.org/10.1017/S0889189300004859

Recebido em: 06/05/2018

Aceito para publicação em: 26/11/2019 